\title{
Implementation of Mobile Data Collection System for Disaster Rapid Emergency Response System Using Open Data Kit
}

\author{
$1^{\text {st }}$ Dody Ichwana \\ Dept. of Computer System Engineering \\ University of Andalas \\ Padang, Indonesia \\ dody.ichwana@fti.unand.ac.id
}

\author{
$2^{\text {nd }}$ Tutun Juhana \\ School of Electrical Engineering and Informatics \\ Bandung Institute of Technology \\ Bandung, Indonesia \\ tutun@stei.itb.ac.id
}

\begin{abstract}
Indonesia is a disaster-prone country. One of the main problems related to disaster in Indonesia is that the country does not yet have a good disaster management that can function optimally in responding to disaster. Therefore, this research is aimed to produce a system that can provide emergency response for disaster management using mobile data collection system. This system would provide crucial and immediate information needed by the decision makers to decide emergency response and recovery procedure. This is a research and development research. The data assessment process is carried out by the assessor at the disaster location using ODK collect. The data then is saved in a mobile communication device. Data can be uploaded by the disaster server network when the connectivity is available. Assessment data can be viewed on the application server through a web admin. The system was generated by considering the law of the state of Indonesia no. 24 Year 2007 concerning disaster management agency planning and regulation by Head of BNPB (Indonesia National Board for Disaster Management) No. 9 Year 2008 on the standard procedure for emergency response team of national board for disaster. Data over disaster occurrence, its massive impact, emergency facilities or supplies needed, post-disaster condition, and a missing victim is provided in these queries. After being tested, it appears that the design and implementation of an emergency disaster response system have been able to run satisfactorily according to system specifications.
\end{abstract}

Keywords-rapid emergency disaster response system, mobile data collection, open data kit (ODK)

\section{INTRODUCTION}

Indonesia is the largest archipelago country in the world, which is prone to natural disasters. Based on Indonesia Disaster Prone Index (IRBI), a tool for disaster analysis in the form of the index, disaster occurred in Indonesia has caused a great loss and causality. IRBI provides information on the type of disaster and its impact [1]. The natural disasters does not only cause many casualties but also impact on social life due to weak economic condition after disaster [2][3][4].

The mitigation of a disaster should be done in planned, integrated, coordinated, and comprehensive manner in order to protect the community form the threats, risk, and impacts of the disaster. This is regulated in the law of Indonesia no. 24 of 2007 on disaster management and PP. 21 of 2008 on the implementation of disaster management.

Information is a basic need in disaster management, most of the information needed for disaster management is spatial information or location[5][6]. For countries that have vulnerability to natural disasters, the use of geospatial technology is an important part of natural disaster management, planning and mitigation [1][7]. One way to reduce disaster risk is to use information technology [8].

Varied information in large number has dominantly become an obstacle in obtaining the accurate information after the disaster occurs. According to [9][10], this causes a problem in the authenticity of the information and the effectivity in collecting the information. Data collection problems during the time of the disaster were: (1) data obtained from multiple sources with different data formats and variations; (2) the information reported by media ahead before the official information from the government by media was inaccurate; (3) estimation over the damage caused by the disaster was still far from being accurate; (4) the inaccurate data had principally worsened the condition; (5) Indonesia has a vast area of 34 provinces [1].

Many regions in Indonesia are not equipped with the technology used to provide current information about a disaster. According to [11], to overcome the obstacles, it is necessary to develop a disaster information management system with the integrated data of disaster. The accurate and reliable information is an essential factor in sustaining a professional and proper response toward disaster [12].

According to [13], dynamicity and punctuality are two main obstacles found during the emergency response. Disaster management should be dynamic and a decision should be made based on the current data. That is to say; the dynamic and data collection have become the foremost challenge in the process of managing a disaster. Therefore, this study aims to generate emergency response system using mobile data collection in sustaining the disaster management procedure.

\section{LITERATURE REVIEW}

\section{A. Disaster Management}

In the law no. 24 the year 2007, the word of disaster is defined as an event or series of events that threaten and disrupt the life and livelihood of a community, which is caused by either natural, non-natural or human factors resulting in human casualties, environmental damage, loss of property, and psychological impact.

Disaster management can be categorized into two types: prior disaster and post-disaster [1] [13]. Management activities before the disaster include mitigation, preparedness, and early warning. On the other hand, 
activities after the disaster are emergency, relief, rehabilitation, and reconstruction. All of these activities are carried out simultaneously and in circular cycles. Subsequently, each stage is closely related. Figure 1 shows the cycles of the disaster management procedure.

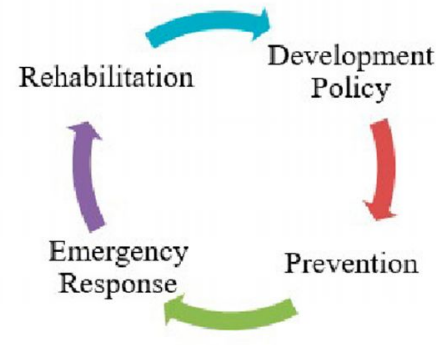

Fig. 1. Disaster Management

\section{B. Google Fusion Tables}

Google Fusion Tables is a cloud-based service for data management and data integration. Fusion tables support services for a significant amount of data integration. Fusion tables are able to upload data from differently varied sources (spreadsheets, CSV, KML, up to $100 \mathrm{mb}$ ). Fusion tables allow users who use services to explore, import and export data from spreadsheets, CSV, and KML forms. Developers can also use the fusion tables API to insert, update, delete and request data. Fusion tables can display data in the form of graphs, maps and timelines while allowing the process of filtering and aggregation. Fusion tables are also able to publish data to other parties [14].

Data requests come from various sources such as fusion tables, websites, stand-alone applications that apply APIs, and a visualization that applies embedded fusion tables inside a web page (e.g. graphs and maps) [14]. Architecture fusion tables can be seen in figure 2 .

The front end dispatcher transforms the request into representation and passes it into the query processing module to generate query requests. Structured back-end data will execute query requests by using synchronously replicated big table servers for storage.

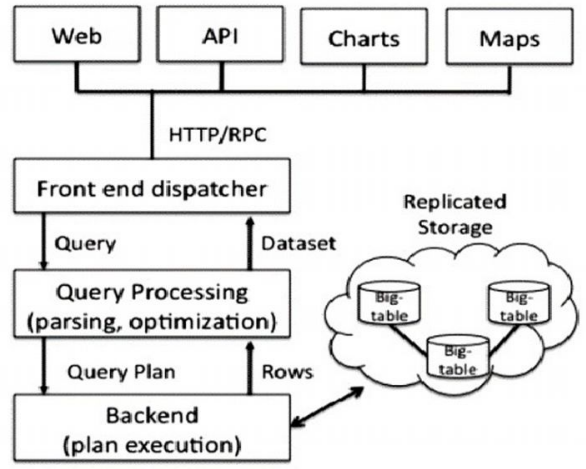

Fig. 2. The architecture of fusion tables [14]

\section{Open Data Kit}

Open Data Kit (ODK) is an extensible open source tool designed for information gathering [15]. ODK consists of tools: collect, aggregate, voice, and build. The translation is as follows [16]:

1. ODK collect is a mobile platform rendering logic applications aiming to collect data. The data collected can be in the form of text, location, image, audio, video, and barcode.

2. ODK aggregate is a "click-to-deploy" application on the server to support data uploading, storing, and transferring cloud-based files on a local server.

3. ODK voice is an application rendering the logic application used to record the sounds in order to respond the user by pressing a button on the keypad.

4. ODK build is a tool for designing drag and drop application to build XML logic file.

The open data kit (ODK) is designed by using modular components so that it can be used in various configurations (including modules not provided by ODK) in order to provide information services and information collection services. The components of ODK are shown in figure 3.

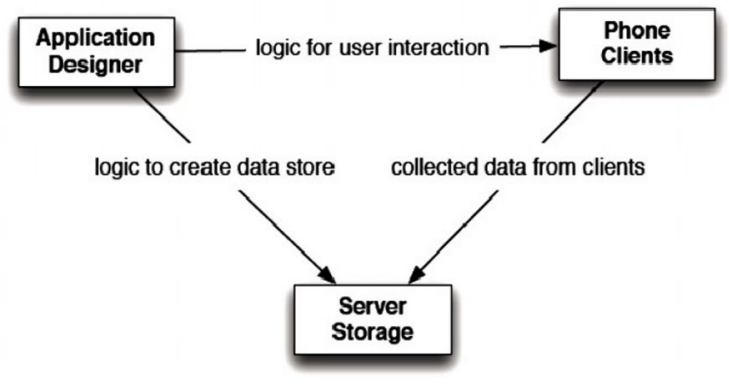

Fig. 3. ODK Components[16]

\section{SYSTEM DESIGN AND DEVELOPMENT}

\section{A. Research Methodology}

The stages were performed to develop this emergency disaster response system (namely SIRBEN): 1) analyzing the required system of refugee management after the disaster. At this stage, one of the obstacles to post-disaster evaluation is that the data collection procedure is still performed manually and not centralized. 2) Designing four forms for post-disaster data collection as follows: a). Data collection format of incidence and disaster impact, b). Data collection format of basic need during the emergency response, c). Data collection format of condition after disaster, and d). Data collection format of missing casualties and family member quest. On this stage, a mobile application was also designed by using ODK collect. Meanwhile, on the server, ODK aggregate and google fusion was used as a storage media for the data. 3). Implementation. This stage was performed on the client and server. On the client, a mobile application was implemented on the devices run with Android platform which was sustained by basic data of SQLite. On the server, the web server was run with PHP and javascript which was sustained by google fusion API as the data storage; 4) Evaluation. An evaluation was performed by executing a trial on the use of the generated system. The black-box test method has been carried out for testing. Evaluation of the system endurance was in the form of evaluating a resource need. In Figure 4 is showed the system development methodology which consists of four stages. 


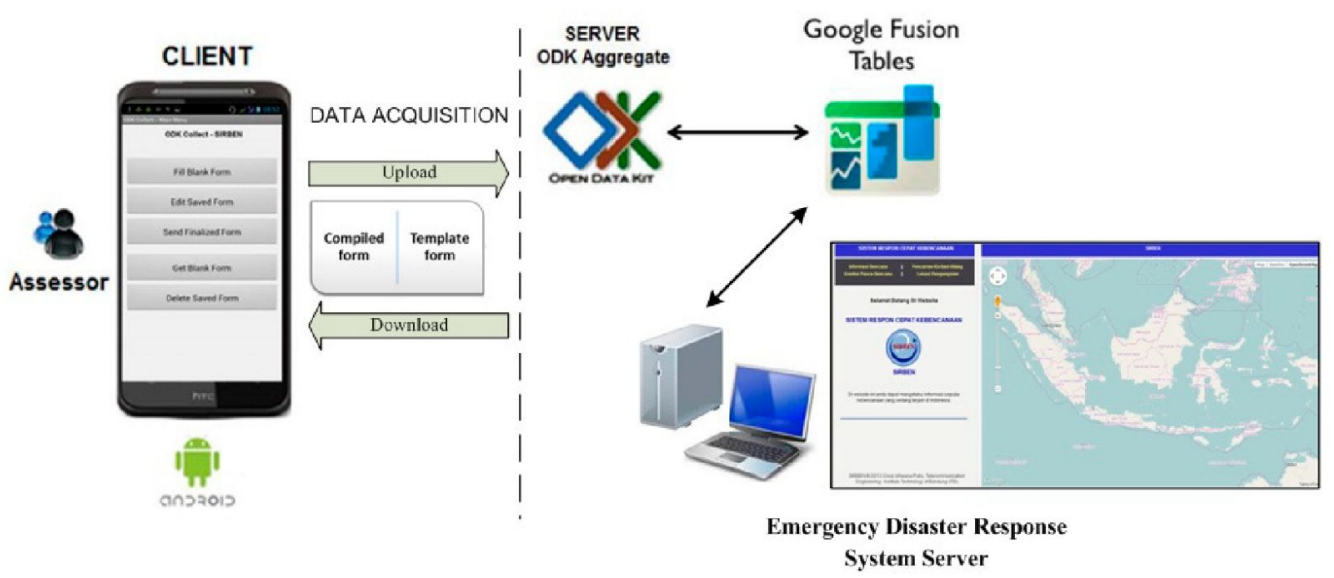

Fig. 5. Architecture of disaster emergency response system

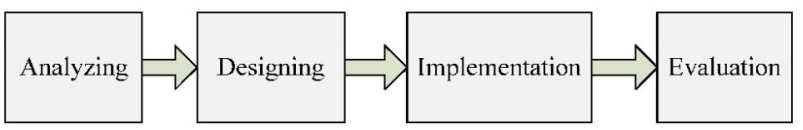

Fig. 4. System development stages

\section{B. Scheme and Need Analysis}

System usage scenario and context model system are in the users' point of view toward the generated system. A scheme is designed based on the need to create soft devices of disaster emergency response. Context model and the scheme are obtained from the conceptual design system built [28][29].

According to [29], the schemes, often called use-cases, provide a description of how a system will be used, a task model and task scenario. The architecture of disaster emergency response system 'SIRBEN' is shown in figure 5. There are two role users or actors connected to the disaster emergency response system, namely (i) assessor of ODK collect, and (ii) admin web SIRBEN. Assessor of ODK collect is an application user who conducts disaster data collection at the disaster site. Context model system is shown in Figure 6.

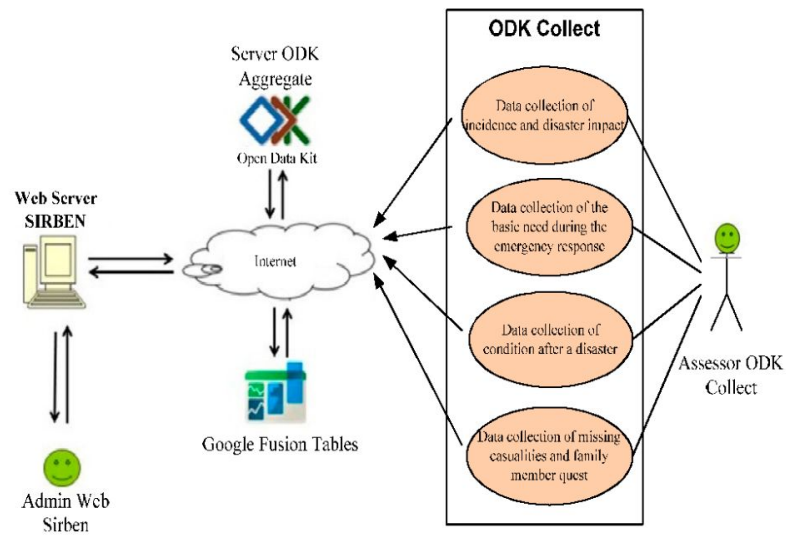

Fig. 4. Context model system

In the first interaction of scheme (an assessor in ODK collect), the assessor performs a selection on the form survey which will be filled. This form consists of data taken from the set of the disaster and refugee shelter. The form survey consists of four forms; (i) data collection of incidence and disaster impact, (ii) data collection of the basic need during the emergency response, (iii) data collection of condition after a disaster, and (iv) data collection of missing casualties and family member quest. After the assessor selects the form survey filled, he will complete the data based on the questions written in the form. After all of the questions have been responded, the assessor will save the data in the mobile devices. The data will be uploaded to the ODK aggregate server which is synchronized with the web server of SIRBEN when it connects to the internet connection.

In the second interaction of the scheme (admin on the SIRBEN web), admin can make a selection on the uploaded data. The selected data will be shown on the web server of SIRBEN. Then, it will be in the form of a menu to help the users in choosing it. It can be seen in the form of a map in the google map which is based on the coordinate sent during the data collection on the set of the disaster and refugee shelter in ODK collect. On the web server, data also can be seen in the form of a graphic to help the decision making in disaster management. The interaction between the assessor and system can be seen in Table I and Table II. Use-case system can be seen in Figure 7 and Figure 8.

TABEL I. INTERACTION BETWEEN THE ASSESSOR OF ODK COLLECT AND SYSTEM

\begin{tabular}{|l|l|}
\hline \multicolumn{1}{|c|}{ Scheme } & \multicolumn{1}{c|}{ Information } \\
\hline Fill Data Assessment & Filling data on the form survey \\
\hline Edit Data Assessment & Selecting data on the form survey \\
\hline Delete Data Assessment & Deleting data on the form survey \\
\hline Upload Data Assessment & Uploading data to the ODK aggregate server \\
\hline $\begin{array}{l}\text { Download Data } \\
\text { Assessment }\end{array}$ & $\begin{array}{l}\text { Downloading the blank form survey form } \\
\text { the ODK aggregate server }\end{array}$ \\
\hline
\end{tabular}

TABEL I. INTERACTION BETWEEN THE ADMIN OF SIRBEN WITH WEB SYSTEM

\begin{tabular}{|c|l|}
\hline \multicolumn{1}{|c|}{ Scheme } & \multicolumn{1}{c|}{ Information } \\
\hline Check Data Assessment & $\begin{array}{l}\text { In this process, SIRBEN admin can view the } \\
\text { assessment done by the assessor team. } \\
\text { Moreover, each data on the table of data } \\
\text { assessment can be chosen to get more } \\
\text { detailed information. }\end{array}$ \\
\hline
\end{tabular}




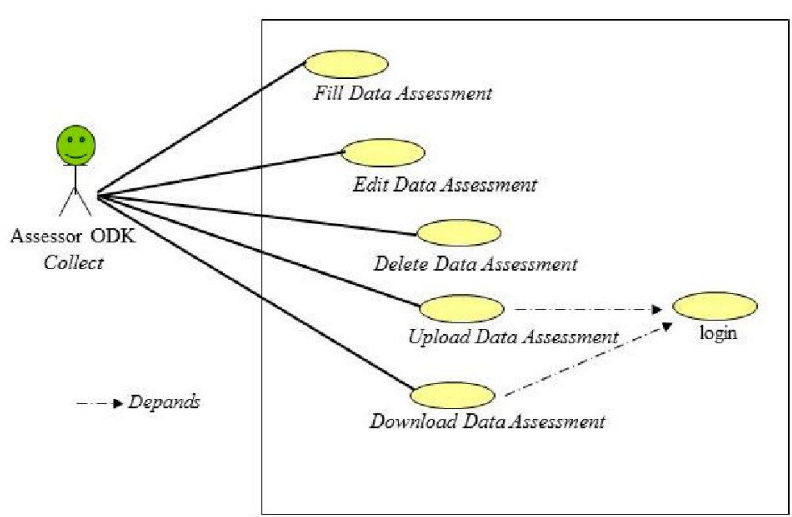

Fig. 5. Use case assessor ODK Collect

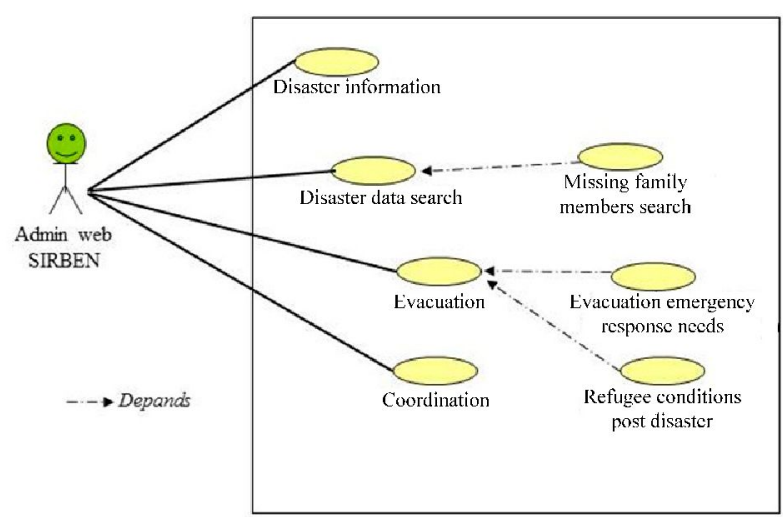

Fig. 6. Use case admin web SIRBEN

\section{RESULT}

The implementation procedure of emergency disaster response system (SIRBEN) was based on the design result and scheme arranged. ODK collect used on mobile devices is to collect information about pre-designed forms. In the initial view of ODK collect, there are five main menus: (1) fill blank form, (2) edit saved form, (3) send ODK finalized form, (4) get a blank form, and (5) deleted saved form. Figure 9 shows the ODK collect form survey display in the smartphone device app. An example of the form survey and the edit saved form menu are shown in Figure 10 and 11 respectively. After the survey form is sent to the ODK aggregate server, the data will be collected in the database. This data has its data id. Each new survey data is added to the server, and the number of data on the server will also be increased. Data on ODK aggregate cannot be performed on query procedure. Figure 12 shows the results of the form survey sent to the ODK Aggregate server.

In the SIRBEN system, the process of sending data from the assessment results is not directly sent to the SIRBEN server, the data of assesment is firstly stored in the local SQLite-android database.This is a solution if there is no network connectivity at the disaster site. Furthmore, by storing the results of the data assessment on the local database first and then sending it to the server of SIRBEN after the assessment process is completed, it will make the assessment process more smooth because the SIRBEN only works locally. If the sending data is carried out in real time, it will take time for the device to continuously maintain or search for network connectivity. The real time of process sending data will make the mobile device battery more wasteful because of the wifi or network features that must continue to live during the assessment process.

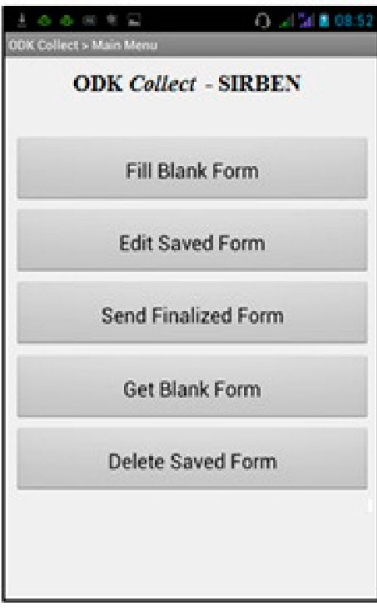

(a). Main menu display

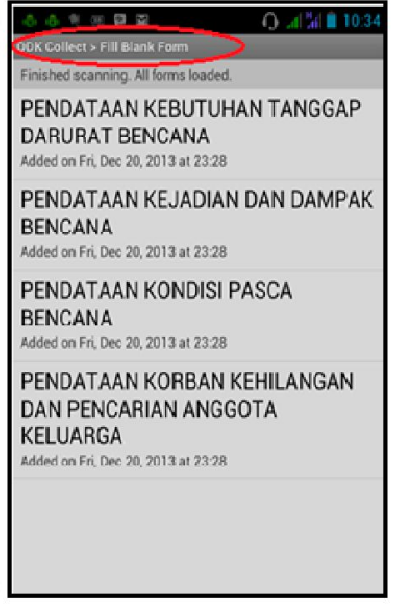

(b). List form survey of disaster data collection
Fig. 7. The application outlook of data collection in smartphone Android

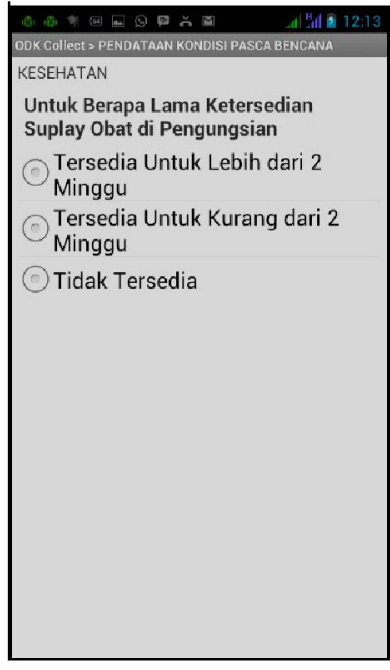

Fig. 10. Form survey

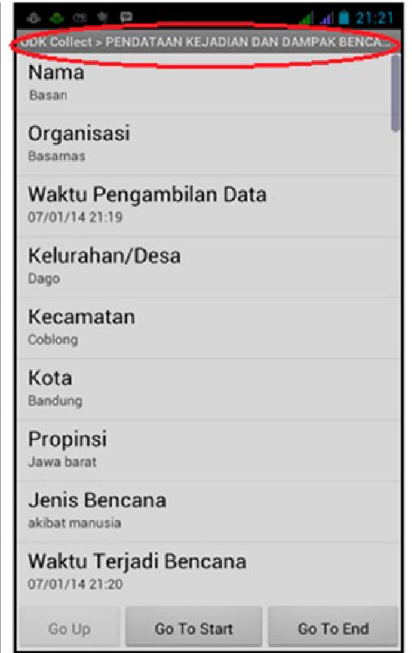

Fig. 11. Form survey edited
Exporting the data on ODK aggregate to google fusion table allow the data query procedure by the SIRBEN web server. Every table in google fusion tables has its id. This id is used in the program to identify the data in the google fusion tables used. The process of querying data from a server to google fusion tables is done by using Google API.

The data in google fusion tables will be synchronised with the data on ODK aggregate so that any added data performed by the assessor will be updated instantly in google fusion tables. Figure 13 shows a picture of google fusion tables data synchronised with aggregate ODK data.

The user interface displayed on the sirben server application uses hypertext preprocessor (PHP). By using the query library when the application is running, the first display appeared is the main page containing explanation of the application of SIRBEN. 


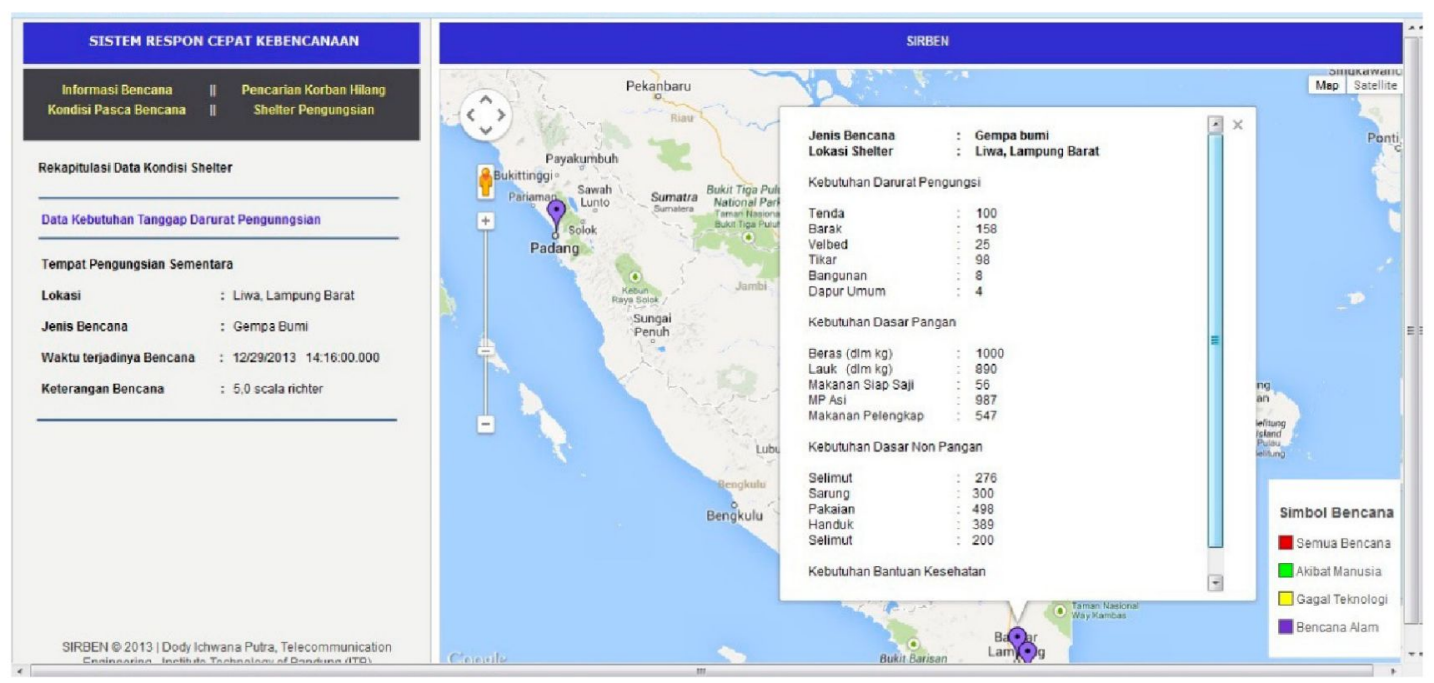

Fig. 14. Displays of the information on shelter conditions after a disaster

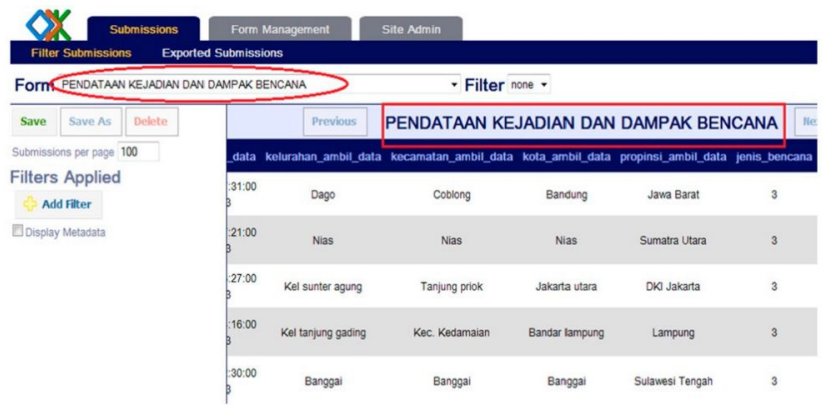

Fig. 12. The form survey data sent to aggregate ODK Server

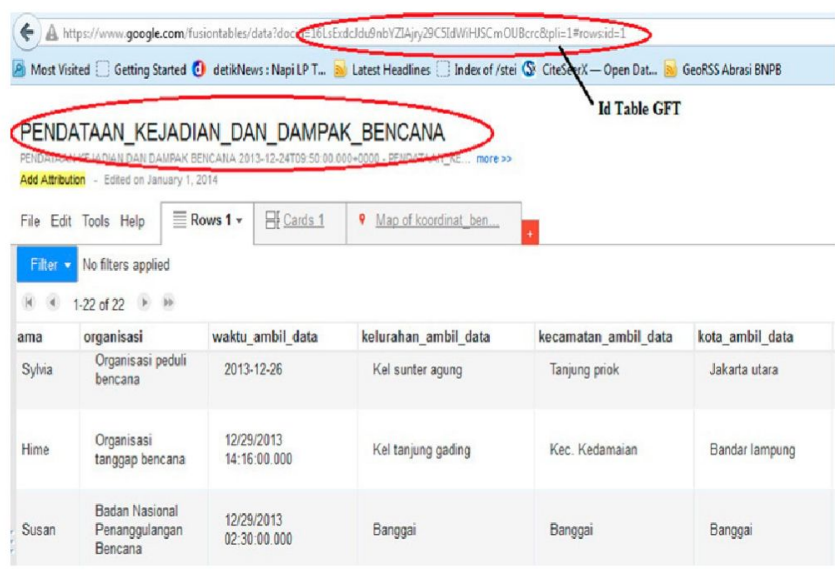

Fig. 13. Google fusion tables data synchronized with aggregate ODK data

The main view of the victim report application server is also created in the same procedure. Based on the results of implementation, each part of the evaluation report will be displayed in the form of a report list, details of each report and report based on coordinates on google maps.

System functional performance testing is done by the black-box method. Black-box testing is conducted aiming to see the similarity of input provided by the system with the expected output. This test is carried out in the scale of application development. Limitation of this testing, the testing has not been carried out in the real disaster situations. The results of the smartphone application black-box testing can be seen in the table III.

TABEL III. RESULT OF BLACK-BOX TESTING

\begin{tabular}{|c|c|c|}
\hline Action & Expectation & Status \\
\hline $\begin{array}{l}\text { Fill out a survey } \\
\text { form }\end{array}$ & $\begin{array}{l}\text { the application will display a survey } \\
\text { form and a list of questions will } \\
\text { appear in the survey form }\end{array}$ & Success \\
\hline $\begin{array}{l}\text { Change the data in } \\
\text { the survey form }\end{array}$ & $\begin{array}{l}\text { The application will display the } \\
\text { results of the data changes }\end{array}$ & Success \\
\hline $\begin{array}{l}\text { Delete the data in } \\
\text { the survey form }\end{array}$ & $\begin{array}{l}\text { The application delete data in the } \\
\text { survey form }\end{array}$ & Success \\
\hline $\begin{array}{l}\text { upload the survey } \\
\text { form to the } \\
\text { application server }\end{array}$ & $\begin{array}{l}\text { The survey form is received on the } \\
\text { application server }\end{array}$ & Success \\
\hline $\begin{array}{l}\text { Download the } \\
\text { survey form from } \\
\text { the application } \\
\text { server }\end{array}$ & $\begin{array}{l}\text { Downloaded survey forms can be } \\
\text { opened in the smartphone } \\
\text { application }\end{array}$ & Success \\
\hline
\end{tabular}

Testing the application is done by sending data of the evaluation result from mobile applications to the server. Afterwards, the addition of the data will be shown on the page list and the marker that exists on the map page based on the coordinates of the position evaluation. Also, data on the evaluation result can also be viewed based on the location of the building on the map display. Figure 14 shows the appearance of the information on shelter conditions after a disaster. On the list page, the user can select the details button to see comprehensive information of each data entering the server. On this page, users can also delete existing data.

\section{CONCLUSION}

The tests conducted on the server applications indicate that the applications have been running as required. Data from mobile applications can be sent and received by the server satisfactorily. Features that are made in the form of list reports, report details and based coordinate-based data are running proficiently. Therefore, it can be concluded that the 
application has fulfilled the need of actual site scheme where the incoming data can be a reference to the volunteers to perform any emergency response at first hand. For future research, it is necessary to build a rapid search finding nearest shelter location system from the current location of the disaster victims to facilitate the disaster mitigation process.

\section{ACKNOWLEDGMENT}

The research is supported by Faculty of Information and Technology, University of Andalas for publication.

\section{REFERENCES}

[1] National Disaster Risk Management Agency, Risiko Bencana Indonesia (Disasters Risk of Indonesia). Jakarta: Badan Penganggulangan Bencana Nasional, 2016.

[2] Y. Sakai, J. P. Estudillo, N. Fuwa, Y. Higuchi, and Y. Sawada, "Do Natural Disasters Affect the Poor Disproportionately? Price Change and Welfare Impact in the Aftermath of Typhoon Milenyo in the Rural Philippines," World Dev., vol. 94, pp. 16-26, 2017.

[3] R. D. Kusumastuti, Viverita, Z. A. Husodo, L. Suardi, and D. N. Danarsari, "Developing a resilience index towards natural disasters in Indonesia," Int. J. Disaster Risk Reduct., vol. 10, no. PA, pp. 327340, 2014.

[4] D. N. Pascapurnama, A. Murakami, H. Chagan-Yasutan, T. Hattori, H. Sasaki, and S. Egawa, "Integrated health education in disaster risk reduction: Lesson learned from disease outbreak following natural disasters in Indonesia," Int. J. Disaster Risk Reduct., vol. 29, no. March, pp. 94-102, 2018.

[5] K. Sowmya, C. M. John, and N. K. Shrivasthava, "Urban flood vulnerability zoning of Cochin City, southwest coast of India, using remote sensing and GIS," Nat. Hazards, vol. 75, no. 2, pp. 12711286, 2015.

[6] J. . b Li, X. . Tang, Z. . Liu, and M. . Duan, "Application of WebGIS for government emergency management based on web service," Proc. - 2009 Int. Conf. Inf. Eng. Comput. Sci. ICIECS 2009, pp. 1-4, 2009.

[7] I. Frigerio et al., "A GIS-based approach to identify the spatial variability of social vulnerability to seismic hazard in Italy," Appl. Geogr., vol. 74, pp. 12-22, 2016.

[8] E. Shamshiry, B. Nadi, M. Bin Mokhtar, I. Komoo, and H. S. Hashim, "Disaster management base on geoinformatics," 2011 IEEE 3rd Int. Conf. Commun. Softw. Networks, ICCSN 2011, pp. 28-31, 2011.

[9] A. Mansouriana, A. Rajabifardb, and M. J. V. Zoeja, "SDI conceptual modeling for disaster management," Serv. Appl. Spat. Data Infrastructure. Int. Soc. Photogramm. Remote Sens., pp. 125-130, 2005.

[10] J. W. J and M. T. Scholar, "Role of Internet of Things in Disaster Management," 2017.

[11] C. Fan and A. Mostafavi, "Establishing a Framework for Disaster Management System-of-Systems," 2018 Annu. IEEE Int. Syst. Conf., 2018.

[12] C. Fan, "Meta-Network Framework for Analyzing Disaster Management System-of-Systems," 2018 13th Annu. Conf. Syst. Syst. Eng., pp. 372-378, 2018.
[13] Y. S. Yan Cui, Suju Li, Liying Wang, MoQuan Sha, "DISASTER EVENT MANAGEMENT BASED ON INTEGRATED DISASTER REDUCTION 1 . National Disaster Reduction Center of China MCA , Beijing100124, China 2. Satellite Disaster Reduction Application Center, MCA , Beijing 100124, China 3 . Twenty First Century Aero," no. 6, pp. 649-652, 2016.

[14] H. Gonzalez et al., "Google Fusion Tables: Data Management, Integration and Collaboration in the Cloud," in Proceedings of the 1st ACM symposium on Cloud computing., 2010, pp. 175-180.

[15] Y. Hong, H. Worden, and G. Borriello, "ODK Tables: data organization and information services on a smartphone," in Proc. of the 5th ACM Workshop ..., 2011, p. 6.

[16] C. Hartung, Y. Anokwa, W. Brunette, A. Lerer, C. Tseng, and G. Borriello, "Open Data Kit: Tools to Build Information Services for Developing Regions," Proc. Int. Conf. Inf. Commun. Technol. Dev., pp. 1-11, 2010. 